\title{
Electricity Access, Community Healthcare Service Delivery, and Rural Development Nexus: Analysis of 3 Solar Electrified CHPS in Off-Grid Communities in Ghana
}

\author{
Richard Opoku $\mathbb{D}^{1},{ }^{1,2}$ Eunice A. Adjei, ${ }^{1}$ George Y. Obeng, ${ }^{1}$ Luc Severi, ${ }^{3}$ \\ and Abdul-Rahim Bawa ${ }^{4}$ \\ ${ }^{1}$ Department of Mechanical Engineering, Kwame Nkrumah University of Science and Technology, Kumasi, Ghana \\ ${ }^{2}$ The Brew-Hammond Energy Center, College of Engineering, Kwame Nkrumah University of Science and Technology, \\ Kumasi, Ghana \\ ${ }^{3}$ Energy Access Unit, United Nations Foundation, USA \\ ${ }^{4}$ Wa Polytechnic, Upper West Region, Ghana \\ Correspondence should be addressed to Richard Opoku; ropoku.coe@knust.edu.gh
}

Received 19 October 2019; Revised 17 January 2020; Accepted 3 February 2020; Published 1 March 2020

Academic Editor: Ahmed Al-Salaymeh

Copyright $\odot 2020$ Richard Opoku et al. This is an open access article distributed under the Creative Commons Attribution License, which permits unrestricted use, distribution, and reproduction in any medium, provided the original work is properly cited.

Over 600 million people living in sub-Saharan Africa do not have access to electricity. Modern healthcare services, including vaccine refrigeration, which require electricity are therefore lacking in such energy-deprived communities. In this work, analysis has been conducted on how electricity access can help improve healthcare service delivery and rural development, with a case study on 3 different off-grid solar photovoltaic (PV) systems in community-based health planning and services (CHPS) in Ghana. Analysis from this study showed that for the $3.0 \mathrm{kWp}$ solar PV systems installed at the various sites, the in-house electricity consumptions are between 4.30 and $7.58 \mathrm{kWh}$ per day. It was found out that excess electricity generation of $148-304 \mathrm{kWh}$ per month is available and can be used to provide other economic services including phone charging, torchlight battery charging, and small-sized cold storage services to generate income for the maintenance of the systems, which is critical for sustainability of solar PV installations in rural poor communities. The study results also showed that electrified health facilities which are able to provide basic healthcare services have potential impact on community health outcomes and rural development. Assessment conducted at the CHPS compounds revealed that, generally, there is improvement in healthcare service delivery resulting in time savings of 15-43 hours per month for the inhabitants which can potentially be used for productive work. The time savings were more significant in females and children than in males. In many rural agro-based communities in developing countries, female and children are usually the workforce engaged in various farming activities. This paper concludes that access to electricity in CHPS compounds helps to improve community health outcomes and increases time availability for women to engage in productive work that can potentially result in significant socioeconomic activities and rural development.

\section{Introduction}

It is estimated that, worldwide, over 1 billion people do not have access to electricity [1]. In sub-Saharan Africa alone, the number is alarming and stands over 600 million [2], with more than $60 \%$ of them living in rural deprived communities without any hope of grid electricity in the near future. A huge leap-frog and an integrated bottom-up approach with private sector financing [3] is needed in such communities if universal access to modern energy services by 2030 is to be realized [4]

Access to modern energy services has strong link with socioeconomic development of communities [5-9] and more importantly when the energy is put into productive use [10]. In areas where the national electricity grid is not available (off-grid areas), renewable energy solutions [11] including 


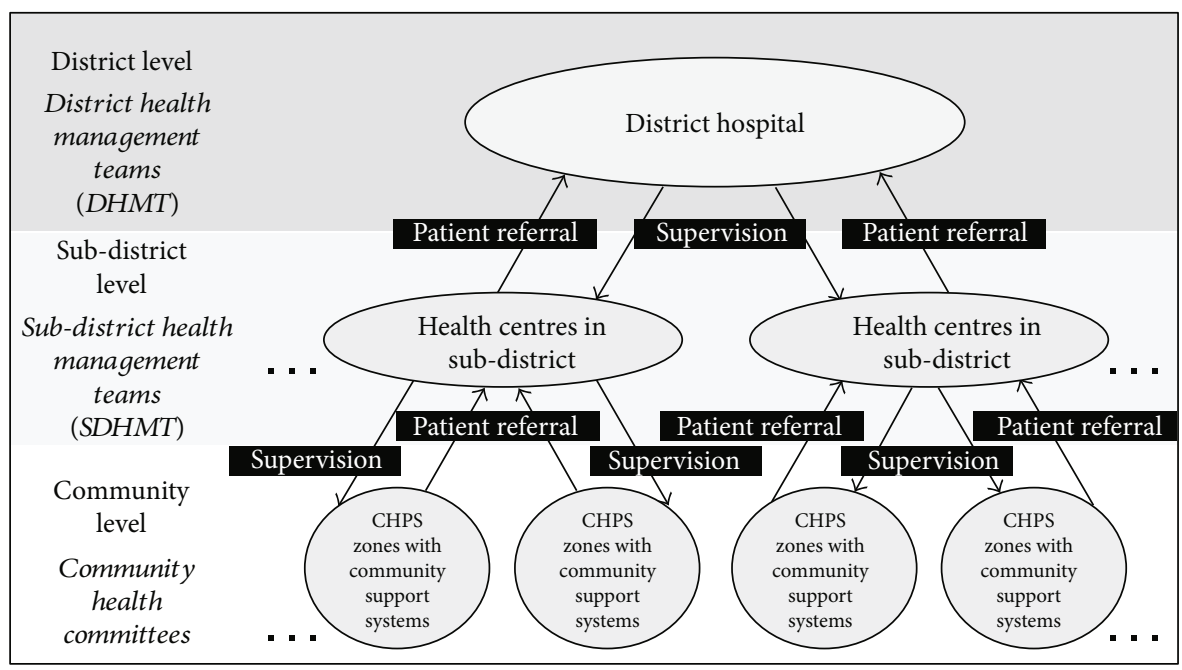

FIGURE 1: Levels of primary healthcare services in the districts in Ghana.

solar energy have been proposed as good options [12-14]. For rural off-grid renewable energy solutions, appropriate energy storage technologies are critical for their reliability [15]. A number of research studies have therefore been conducted on standalone solar PV systems with battery-based energy storage for off-grid electricity access for various applications including water pumping, quality healthcare service delivery, and phone charging $[14,16,17]$.

In the health sector, access to energy is critical for delivering and improving healthcare services and lifesaving interventions [18]. Studies have shown that sustainable development of communities is affected by the well-being of its inhabitants which are often predetermined by the type of energy used [19] and the availability of electrified health facilities [20]. For example, in the studies of Hernández and Siegel [21] and Zhang et al. [22], it has been determined that energy poverty and insecurity has negative impact on people's health and community development [23]. In many countries in sub-Saharan Africa, community-based health facilities are either underelectrified or do not have access to electricity [24, 25]. In cases where some of these remote health facilities have received donor funding for standalone renewable electricity generation systems, the systems have suffered long-term sustainability issues due to poor maintenance practices and ownership responsibilities.

In Ghana, there are a number of community-based healthcare planning and service (CHPS) compounds, which are unelectrified [25]. In 2017, United Nations Foundation (UNF) implemented a pilot project that installed standalone solar PV systems in 3 of these remote off-grid health facilities/CHPS in the Mamprugu Moagduri District in the northern region of Ghana. Since then, the potential impact of the solar PV systems on healthcare service delivery and community development has not been established. In addition, studies on innovative ways of ensuring long-term sustainability of the systems are lacking. The objective of this study is to evaluate how access to electricity in the CHPS compounds has affected healthcare service delivery and rural development in the communities where the standalone solar
PV systems have been installed. Further, a novel and practical approach of using energy service companies (ESCOs) to manage extra electricity generation from the solar PV systems and generate revenue that can be used to maintain them to ensure their long-term sustainability is presented.

\section{Methodology}

2.1. Setup of CHPS Compounds in Ghana. A CHPS compound in Ghana is a community-based healthcare planning and service model that addresses gaps in healthcare delivery for remote rural communities in different districts in the country. There are over 1410 health facilities or CHPS in Ghana [26], with over $50 \%$ of them not having access to electricity. The main objective of CHPS compounds is to achieve universal healthcare coverage, including financial risk protection, access to quality essential healthcare services, and access to safe, selective, quality, and affordable essential medicine and vaccines for all [26].

The CHPS compounds usually deliver healthcare to remote communities with population between 500 and 1800. It is mainly constructed comprising 3 or 4 rooms in a building, with one of the rooms used as accommodation for the community health officer $(\mathrm{CHO})$. The trained $\mathrm{CHO}$ is usually supported by volunteers drawn from the area of service. The CHPS compounds provide basic healthcare including clinical care for minor ailments, vaccination, antenatal services, midwifery, preventive and promotive services, and emergency service deliveries. In situations where a reported case is beyond their capabilities, the case is referred to the district or subdistrict hospitals. Figure 1 shows the levels of primary healthcare in the districts [26].

2.2. The Study Area. The northern part of Ghana is one of the deprived areas in terms of social amenities and modern utility services. There are 27 districts in the three northern regions which have a total land area of $70,384 \mathrm{~km}^{2}$ with total population of over 3 million. The indigenes are mainly farmers cultivating different crops including rice, millet, 
TABLE 1: Electrical appliances at the 3 CHPS in the Mamprugu Moagduri District.

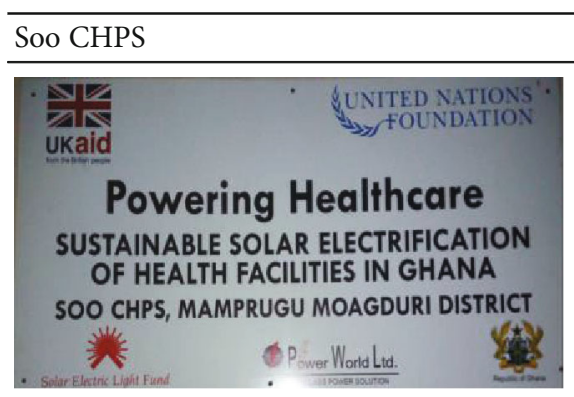

Inside lights: 16 pieces of 12-watt LED bulbs

Outside lights: 10 pieces of 12 -watt LED bulbs

Ceiling fans: 5 pieces of 50 watts each

Television: 2 pieces of 55 -watt 21 -inch TV set

Fridge: 1 piece of 72-liter 70-watt vaccine refrigerator
Namoo CHPS

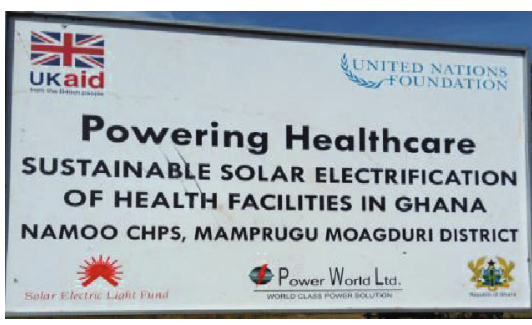

Inside lights: 15 pieces of 12-watt LED bulbs

Outside lights: 10 pieces of 12 -watt LED bulbs

Ceiling fans: 6 pieces of 50 watts each

Television: 1 piece of 55-watt 21 -inch TV set

Fridge: no vaccine refrigerator
Yikpabongo HF

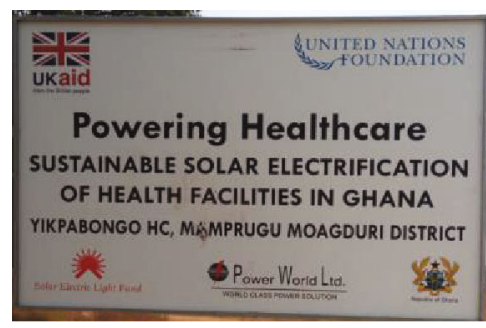

Inside lights: 20 pieces of 12 -watt LED bulbs

Outside lights: 5 pieces of 15 -watt LED bulbs

Ceiling fans: 6 pieces of 50 watts each Television: 2 pieces of 55 -watt 21 -inch TV set

Fridge: 1 piece of 72-liter 70 -watt vaccine refrigerator

TABLe 2: Specifications of the standalone solar PV installations at the CHPS compounds.

\begin{tabular}{|c|c|c|c|}
\hline Solar PV & Battery storage & Inverter/charger & Controller \\
\hline $\begin{array}{l}3.0 \mathrm{kWp} \text { installed; tilted at } 15^{\circ} \text { angle } \\
\text { towards the south } \\
\text { Support structure: } 8 \text {-inch ID }(8.63 \text {-inch } \\
\text { OD) SCH40 steel pipe with } 3.5 \text {-feet base } \\
\text { plate; } 4.5 \text {-feet-deep concrete foundation }\end{array}$ & $\begin{array}{l}48 \mathrm{~V} \text { configuration; } 38.4 \mathrm{kWh} \\
\text { total installed capacity; } 24 \text { pieces } \\
\text { of } 2-\mathrm{V} \text { cell, } 800 \text { ah, gel-type } \\
\text { battery }\end{array}$ & $\begin{array}{l}3.0 \mathrm{~kW} \text {; FLEXpower ONE hybrid inverter; } \\
48 \text { VDC input, and } 230 \text { VAC } 50 \mathrm{~Hz} \text { output; } \\
\text { overload capacity of } 5.75 \mathrm{~kW} \text { (surge) }\end{array}$ & $\begin{array}{l}\text { MPPT } 80 \text { amps } \\
\text { max. output } \\
\text { current, } 48 \\
\text { VDC }\end{array}$ \\
\hline
\end{tabular}

maize, sorghum, peanut, and vegetables. Healthcare service delivery is a challenge in the remote northern part of Ghana due to unavailability of the national electricity grid, in addition to low-economic activities in many parts of the region $[26,27]$. It is also important to highlight that ambient temperatures in the northern region are very high and can get up to $35^{\circ} \mathrm{C}$ [28], which is not favorable for storage of drugs. Controlled storage rooms, either ventilated rooms or vaccine refrigeration, are a requirement for proper storage of drugs [29, 30].

Out of the over 185 CHPS compounds in the remote northern part of Ghana [31], only a few of them have access to or close to the national electricity grid. In a feasibility study conducted by United Nations Foundation [25], on electrification of off-grid health facilities in Ghana, the financial analysis (cost-benefit comparison) revealed that for health facilities located beyond $5 \mathrm{~km}$ from the national grid, standalone solar PV systems were financially the best options, whilst for facilities within $5 \mathrm{~km}$ reach to the grid, it was financially viable to connect them to the national grid. In the Mamprugu Moagduri District, in particular, there are 3 health facilities/CHPS without access to grid electricity and are over $10 \mathrm{~km}$ from the national grid. They are Soo CHPS, Namoo CHPS, and Yikpabongo health facility. In 2017, through a pilot project, UNF facilitated the wiring of the facilities and installation of electrical appliances and standalone solar PV systems. The solar PV system design and installations were executed by Solar Electric Light Fund
(SELF), USA, through its local partner, Power World Limited, in Ghana. The types of electrical appliances installed at the CHPS compounds are presented in Table 1.

2.3. Standalone Solar PV Systems at the 3 CHPS Compounds. The standalone solar PV systems were designed and installed at the three health facilities/CHPS compounds based on their appliance electrical loads and energy needs. To accommodate potential future energy demands, $20 \%$ overhead was factored into the design. Table 2 presents the specifications of the same-sized solar PV system installations at the 3 sites. Figure 2 also shows an example of the solar PV installation at one of the sites. The unit cost of installation of solar PV system components in Ghana is also presented in Table 3.

2.4. Solar System Configuration. The installed inverter for the solar system consists of standardized components from Outback Power. These systems called "FLEXpower One" consist of Outback VFXR3048E inverter-chargers with a nominal capacity of $3000 \mathrm{~W}, 48 \mathrm{VDC}$ input, and $230 \mathrm{VAC} 50 \mathrm{~Hz}$ output.

The Outback VFXR3048E is a hybrid inverter-charger that is capable of being connected to the utility grid as and when the opportunity arises, making the systems futureproof and adaptable in a changing energy market. The built-in AC charger can receive energy from any available AC power source such as the grid or a generator, to help charge the batteries via the advanced 4-stage battery charging system (bulk, absorb, float, and equalization). 


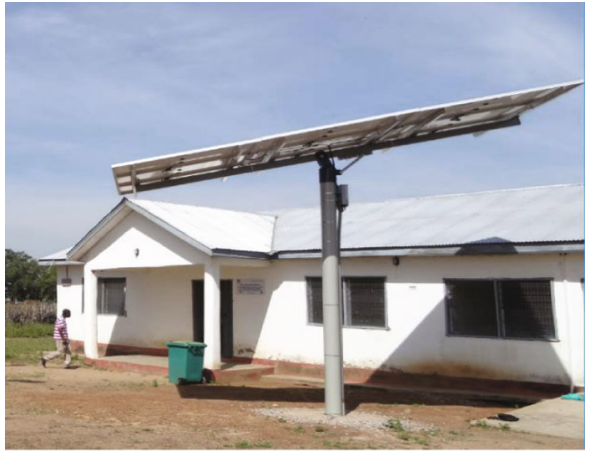

(a) Solar PV array

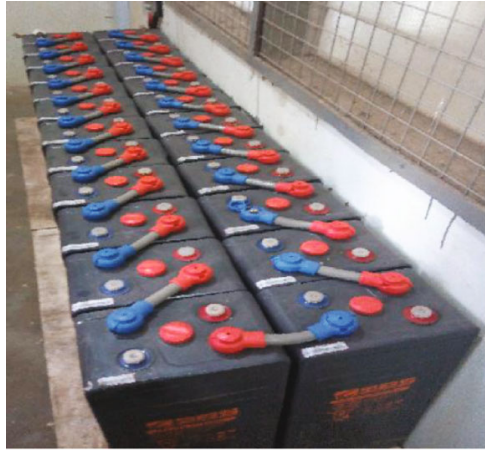

(b) Battery storage

Figure 2: Standalone solar PV system at the CHPS compounds.

TABLE 3: Unit cost per component of solar PV system installation in Ghana.

\begin{tabular}{|c|c|}
\hline Variable & Cost/value \\
\hline Cost of solar PV modules & US\$ $0.48-0.55$ per Wp of solar panels, based on brand and specific PV technology \\
\hline Cost of battery & US\$ $134-152$ per kWh, deep cycle, gel-type \\
\hline Cost of hybrid inverter & US\$ $210-270$ per kW of hybrid inverter, based on brand \\
\hline $\begin{array}{l}\text { Cost of cables for installing PV, inverter, } \\
\text { and battery system }\end{array}$ & $\begin{array}{l}\text { US\$ 350-450 per kW system, based on data obtained from licensed PV installers } \\
\text { in Ghana }\end{array}$ \\
\hline Mounting poles and accessories & $\begin{array}{c}\text { US\$ } 100-140 \text {, per meter length of 8-inch ID pipe, depending on material type } \\
\text { and specifications }\end{array}$ \\
\hline Labour cost for installation of solar PV system & $\begin{array}{l}\text { US\$ } 350-480 \text { per } \mathrm{kW} \text { of solar system installation, including battery and inverter. } \\
\text { Installation cost varies depending on the qualification of the installer }\end{array}$ \\
\hline $\begin{array}{l}\text { Maintenance cost for solar PV system } \\
\text { (cleaning of panels) }\end{array}$ & $\begin{array}{c}\text { US\$ 150-200 per kWp of PV array per year, based on data obtained from } \\
\text { licensed solar companies in Ghana }\end{array}$ \\
\hline
\end{tabular}

The FLEXpower systems also come standard with Outback's FLEXnet DC (FNDC) battery monitor that tracks the inflow and outflow of energy to the battery and provides monitoring of the battery state of charge, instantaneous and historical summary data on energy flows, and other battery assessment parameters such as "Days Since Full" which tracks the number of days since the battery has received a full charge.

Data obtained from the installations (using the SD memory card in the FLEXpower inverters) were used to determine the in-house electricity use and excess electricity that could potentially be used to create other economic activities to generate income.

The final energy output $\left(E_{\mathrm{AC}}\right)$ of the solar PV systems which is the amount of alternating current (AC) power produced over a given period of time was computed using the following equation [32]:

$$
E_{\mathrm{AC}}=\sum_{t=0}^{N} E_{\mathrm{AC}, t},
$$

where $E_{\mathrm{AC}, t}$ is the AC energy output at time $t$ and $N$ is the period in this case a one-year period. The results obtained from the analysis of the standalone solar PV systems at the 3 health facilities/CHPS compounds are presented in Section 3 .
2.5. Assessing the Impact of the Solar PV System on Healthcare Service Delivery. In order to ascertain how the installations of the solar PV systems at the CHPS compounds have impacted healthcare services delivery and community development, records of outpatients before and after the system installation, spanning a 14-month period, were collected and analyzed. Data on reported cases including malaria, cholera, and snake bites, which are common in the communities, were gathered. In addition, through a community survey, data were collected and analysis conducted on time savings for productive work, as a result of improved health of the inhabitants, which otherwise would have been spent caring for their family members admitted at the CHPS compounds. Equations (2) and (3) were used to compute the mean values and the standard errors associated with the outpatient data, respectively [33].

$$
\begin{aligned}
& \bar{X}=\frac{1}{N} \cdot \sum_{i=1}^{N} X_{i}, \\
& \sigma_{s}=\frac{t}{\sqrt{N}} \times \sqrt{\frac{\sum_{1}^{N}\left(X_{i}-\bar{X}\right)^{2}}{N-1}},
\end{aligned}
$$

where $X_{i}$ is the $i^{\text {th }}$ data point, $\bar{X}$ is the mean value, $N$ is the number of data points, and $t$ depends on $N$ and the 


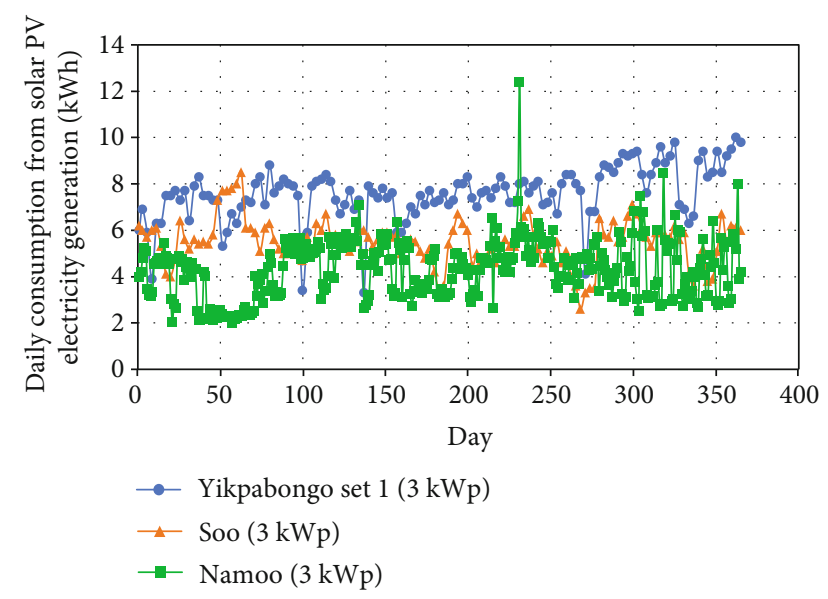

FIGURE 3: Daily in-house consumption from solar PV electricity generation.

confidence level (in this case 95\%). A value of $t=2.57$ was used from statistical tables [34].

In the community survey, data were collected on the gender and age of the respondents and their occupation, among others. In addition, some relevant questions asked were as follows:

(i) Have you visited the CHPS compound for treatment before?

(ii) When was the last time you visited the CHPS compound for treatment?

(iii) How do you rate the service delivery at the CHPS compound: high, good, adequate, or inadequate?

(iv) Do you think electricity access at the CHPS compound has improved healthcare services delivery in your community?

(v) How many hours do you think you save because of improved healthcare that reduces the number of times you fall sick to go to the CHPS compound?

2.6. Hypothesis Testing. It is generally claimed that in rural agro-based communities, females and children play pivotal roles in their community development [35-37], due to their substantial involvement in both subsistence and commercial farming activities. It is therefore hypothetically inferred that better health conditions of females and children lead to more time availability that can potentially be used for productive work and socioeconomic development in rural agro-based communities than men. To test the statistical significance of this one-tailed hypothesis [38], we formulate the null $\left(\mathrm{H}_{0}\right)$ and alternate $\left(\mathrm{H}_{\mathrm{a}}\right)$ hypotheses as follows:

(i) $H_{0}$ : improved health conditions of females and children do not lead to more time savings (availability) that can potentially be used to undertake productive activities for socioeconomic development in rural agro-based communities than males. (ii) $H_{a}$ : improved health conditions of females and children lead to more time savings (availability) that can potentially be used to undertake productive activities for socioeconomic development in rural agro-based communities than males.

The null and alternate hypotheses are mathematically expressed as

$$
\begin{aligned}
& \mathrm{H}_{0}: \mu_{\mathrm{f}} \leq \mu_{\mathrm{m}}, \\
& \mathrm{H}_{\mathrm{a}}: \mu_{\mathrm{f}}>\mu_{\mathrm{m}},
\end{aligned}
$$

where $\mu_{\mathrm{f}}$ and $\mu_{\mathrm{m}}$ represent the population mean of the females and males, respectively.

The hypothesis presented in Equation (4) was tested by computing the $Z$-score for two means as given by Equation (5) $[38,39]$ :

$$
Z=\frac{\left(\overline{x_{\mathrm{f}}}-\overline{x_{\mathrm{m}}}\right)-\left(\mu_{\mathrm{f}}-\mu_{\mathrm{m}}\right)}{\sqrt{\left(\sigma_{\mathrm{f}}^{2} / N_{\mathrm{f}}\right)+\left(\sigma_{\mathrm{m}}^{2} / N_{\mathrm{m}}\right)}},
$$

where $\overline{x_{\mathrm{f}}}$ and $\overline{x_{\mathrm{m}}}$ are the sample means for the females and males, respectively. Equations (4) and (5) are also used to test the hypothesis between children and males by replacing the population and sample means, as well as the variance for the females with that of children using $\mu_{\mathrm{c}}, \overline{x_{c}}$, and $\sigma_{\mathrm{c}}^{2}$, respectively. With the population variance $\left(\sigma^{2}\right)$ for the grouped data unknown, it was estimated using the sample variance $\left(s^{2}\right)$.

$$
s^{2}=\frac{\sum_{i=1}^{N} f_{i}\left(m_{i}-\bar{x}\right)^{2}}{N-1},
$$

where $f$ is the frequency of response, $m_{i}$ is the class midpoint, $\bar{x}$ is the sample mean, and $N$ is the sample size. The results obtained for this study are presented in the following sections.

\section{Results and Discussions}

3.1. In-House Electricity Consumption. The daily in-house (CHPS compounds) solar PV electricity consumption data were obtained from the SD card data loggers installed in the inverters from the different sites. Figure 3 shows the daily solar electricity consumption by the Namoo, Soo, and Yikpabongo CHPS compounds.

From Figure 3, it is observed that on the average, inhouse electricity consumption of $4.30 \mathrm{kWh}, 5.52 \mathrm{kWh}$, and $7.58 \mathrm{kWh}$ exist for Namoo, Soo, and Yikpabongo set 1 installations, respectively. The variations in the magnitudes of the in-house electricity consumption at the 3 sites are due to differences in quantities of the electrical appliances.

3.2. Sustainability of the Solar PV Systems. In many countries in Africa, donor-provided community-based projects usually face the challenge of ownership and system sustainability responsibilities. In particular, electricity generation systems in health facilities in rural off-grid areas in many developing 


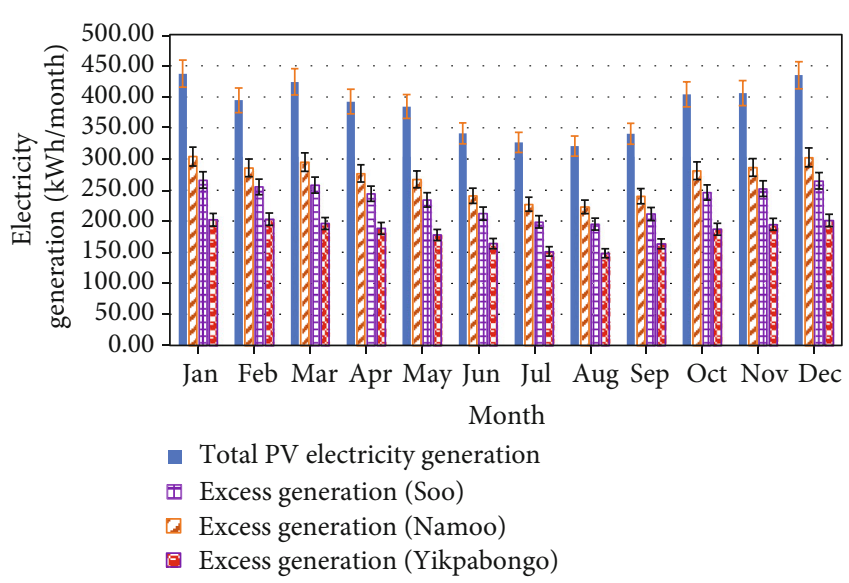

FIgURE 4: Total electricity generation and excess from the $3 \mathrm{kWp}$ solar PV systems.

TABLE 4: End user electricity tariffs.

\begin{tabular}{lll}
\hline $\mathrm{kWh} /$ month & & \\
$0-50$ & $\mathrm{GHp} / \mathrm{kWh}$ & 30.7780 \\
$51-300$ & $\mathrm{GHp} / \mathrm{kWh}$ & 61.7488 \\
$301-600$ & $\mathrm{GHp} / \mathrm{kWh}$ & 80.1380 \\
$601+$ & $\mathrm{GHp} / \mathrm{kWh}$ & 89.0422 \\
Service charges & & \\
$\quad$ Lifeline consumers & $\mathrm{GHp} /$ month & 213.0000 \\
Other residential consumers & $\mathrm{GHp} /$ month & 703.8906 \\
\hline
\end{tabular}

countries suffer from long-term sustainability issues due to limited budget for regular maintenance. Failure of minor parts which could cost less than $\$ 10$ to replace can render the whole system unusable when funds are not provided. In the works of Brew-Hammond [40], it was suggested that energy systems in rural off-grid areas can be sustained if they are used to generate productive economic activities that are able to raise cash flow (income) for maintenance and replacement of faulty parts.

In the case of the solar PV systems installed at the 3 CHPS compounds, analysis was conducted on how energy service companies (ESCOs) can be used to address this issue. The use of ESCOs to manage the extra electricity instead of the healthcare providers presents an advantageous marketplace innovation because they (ESCOs) have the technical expertise to do proper operation and maintenance of the systems. ESCOs would also have the right capacity to identify technical problems with the solar system, procure parts from the market, and implement appropriate maintenance solutions. In addition, the proposal to use ESCOs to manage the extra electricity for revenue generation is to avoid distraction to the healthcare workers who have core mandate of healthcare service delivery at the CHPS compounds.

Analysis was conducted on the total electricity generation from the solar PV installations to determine potential excess electricity that can be sold to generate income. Figure 4 shows the total electricity generation from the solar PV systems and

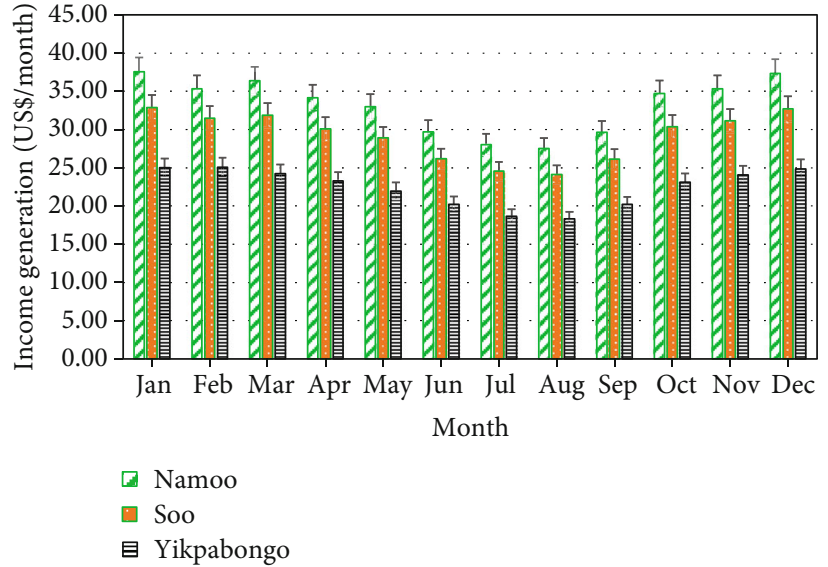

Figure 5: Income generation from excess PV electricity generation.

the excess generation for each of the sites that could potentially be used to create economic activities.

From the result of Figure 4, it is observed that the total seasonal electricity generation from the same size $(3.0 \mathrm{kWp})$ of installed solar PV systems at the sites is between 320 and $437 \mathrm{kWh}$ per month. Based on the current in-house electricity consumption at the various sites (presented in Figure 3), it is determined that seasonal excess PV electricity generation of $222-304 \mathrm{kWh} /$ month, $195-266 \mathrm{kWh} /$ month, and $148-203 \mathrm{kWh} / \mathrm{month}$ are obtainable for Namoo, Soo, and Yikpabongo, respectively, and could be explored to create other economic activities in the communities. Further analysis was therefore conducted on the potential of income generation from the excess electricity, as presented in the following section.

\subsubsection{Income Generation Potential with the Excess $P V$} Electricity. In the analysis of the income generation potential with the excess electricity from the solar PV installations at the three sites, the electricity tariffs for the residential sector in Ghana as published by the Public Utilities Regulatory Commission [41], in Ghana pesewas (GHp), were used (Table 4).

It is important to note that in Ghana, the electricity tariffs are different for different customer categories. For the purpose of the financial analysis, the local currency (Ghana Cedis-GHS) was converted to US\$ using Ghana Commercial Bank exchange rates (US cent 1.0 is equivalent to GHp 5.5). Figure 5 shows the potential monthly average income generation from the excess solar PV electricity generation at the 3 sites if sold at the current tariff rate for the residential sector in Ghana.

From the result of Figure 5, it is determined that average revenues of US\$ 34 , US\$29, and US\$22 per month could be generated from the Namoo, Soo, and Yikpabongo sites, respectively. In total, annual revenue generations in the range of US\$270-405 are achievable for the sites from the sale of the excess electricity. It is important to emphasize that this revenue generation is very substantial considering the fact that the inhabitants of the communities where the study was carried out fall below the poverty line of average earnings of US\$1 per day. 
TABle 5: Proposed economic activities for the ESCOs for the 3 sites.

\begin{tabular}{lccc}
\hline CHPS compound & $\begin{array}{c}\text { Excess electricity } \\
(\mathrm{kWh} / \mathrm{month})\end{array}$ & $\begin{array}{c}\text { Excess electricity } \\
(\mathrm{kWh} / \text { day })\end{array}$ & Proposed economic activities for the 3 sites \\
\hline Namoo $^{*}$ & $222-304$ & $7.4-10.1$ & Charging of phones at a fee of US cents 10.0 per day \\
Soo & $195-266$ & $6.6-8.9$ & Charging of rechargeable lamp batteries at US cents 12 per day \\
Yikpabongo & $148-203$ & $4.9-6.8$ & Namoo site can run a small vaccine refrigerator of 50 W capacity* \\
\hline
\end{tabular}

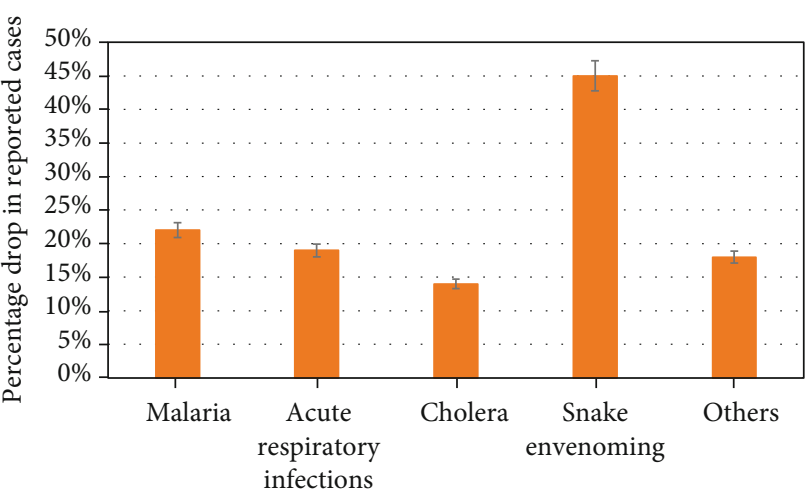

Figure 6: Percentage drop in reported cases after access to electricity at the CHPS.

From this analysis, it is argued strongly that for the huge investment made by UNF on the solar PV systems to be sustainable, private energy service companies (ESCOs) should be engaged to manage the excess electricity in order to raise revenue for operation and maintenance of the systems. It is however recommended that under such arrangements, the PV systems should incorporate electrical load divider devices that allow only the excess electricity to be used by the ESCOs, in order not to overdrain the system to jeopardize the core operations of the CHPS compounds.

The following section presents the scenarios under which an ESCO can create an economic activity from the excess PV electricity generation.

3.2.2. Proposed ESCO Model. In Ghana, under the power sector regulatory framework [42], two (2) main companies ECG (Electricity Company of Ghana) and NEDCO (Northern Electricity Distribution Company) have the mandate to sell power from the national grid to consumers. However, for standalone systems for off-grid communities, a potential consumer can engage an ESCO for electricity power systems under mutual financial agreement. However, that ESCO has to be licensed with the Ghana Energy Commission to be able to operate. Many off-grid households and facilities therefore have different financing arrangements with ESCOs that enable them to get access to electricity including the payand-use model.

Indigenes in many remote off-grid areas in Ghana usually use rechargeable lamps for lighting in the night. In addition, some of them use phones for communication. The rechargeable batteries of the lamps and the phones are sent through local couriers at a fee to have them charged in nearby cities (with grid electricity) which are usually about 10-25 kilometers away. The fee for charging a phone and the rechargeable

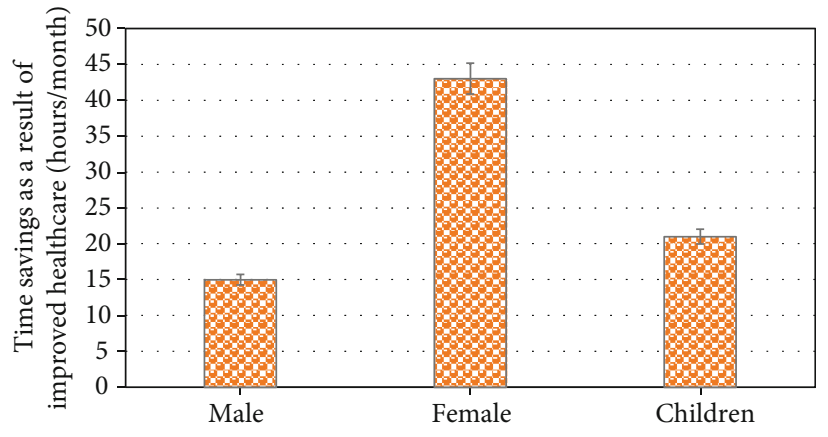

FIGURE 7: Monthly mean time savings in hours for different groups of people.

lamps are 80 and 100 Ghana pesewas, respectively, per day (US cents 14.5 and 18.2 equivalent). From the result presented in Figure 4 with different available excess PV electricity generation for the 3 sites, a marketplace innovation using the ESCOs is proposed (Table 5).

The proposed fees for charging the appliances per day by the ESCOs are lower than the current practice of charging appliances by the inhabitants when they send them to the cities. The reduced charging fee (about 31-34\% reduction, compared to charging at the cities) is to encourage the inhabitants to charge their phones and torchlights with the excess solar PV electricity generation at the CHPS compounds.

As mentioned earlier, one of the objectives of this study is to find out the nexus between electricity access, health of the people, and community development. The results obtained are presented in the following section.

3.3. Impact of Electricity Access on Healthcare Service Delivery and Community Development. Analysis was conducted on how access to electricity at the CHPS compounds has improved healthcare service delivery to the people and inherently its impact on health outcomes and community development. Primary data were collected from the number of cases reported at the CHPS compounds. Improvement in the healthcare service delivery was measured using the drops in reported cases at the CHPS compounds. Figure 6 shows the percentage drops in the common diseases prevalent in the communities.

From the result of Figure 6, it is observed that there have been drops (14-45\%) in the common ailments in the communities, which could be ascribed to multiple factors. From the interactions during the community survey, the indigenes reported that they have experienced improved health outcomes due to electricity access at the CHPS compounds. The improved health outcomes could be attributed to 
TABLE 6: Results for statistical significance of time savings among females, children, and males.

\begin{tabular}{lccc}
\hline & Females & Male & Children \\
\hline Sample size & 52 & 48 & 45 \\
Sample mean & 43.1 & 15.4 & 21.3 \\
Standard deviation & 2.7 & 5.2 & 4.9 \\
Calculated $Z$-score of females and children compared to males & 33.0 & 5.6 \\
Computed $P$ value & $P=0<0.05$ & $P=0<0.05$ \\
$95 \%$ confidence interval & $26.056<\mu_{\mathrm{f}}-\mu_{\mathrm{m}}<29.344$ & $3.847<\mu_{\mathrm{c}}-\mu_{\mathrm{m}}<7.953$ \\
\hline
\end{tabular}

improved healthcare service delivery that provides basic services including proper ventilation of drug storage rooms for medications that require storage temperatures below $30^{\circ} \mathrm{C}$. In addition, the electricity access allowed proper refrigeration of vaccines which require temperatures in the range of $3-7^{\circ} \mathrm{C}$. Information gathered from the community nurses was that before the installation of the solar PV systems, they had to travel long distances (over $10-25 \mathrm{~km}$ ) to nearby cities to buy ice to keep the vaccines cooled in food flasks, with unregulated temperatures. This practice usually rendered the drugs ineffective resulting in frequent returns of same attended issues. In particular, vaccines for treating snake bites were usually ineffective because of the improper refrigeration practice.

In order to ascertain how the improved healthcare has impact on community development, a survey was conducted with the inhabitants in the communities. The survey results are reported in terms of time savings spent on healthrelated issues as a result of more effective healthcare delivered by the electrified CHPS compounds. Figure 7 shows the monthly mean time savings, in hours. It is important to mention that because of lack of record keeping by the inhabitants, the community survey did not allow for measurement of desired econometric parameters. However, amidst lack of econometric information, data on time savings by the inhabitants, which otherwise would have been used to take care of themselves or their family members at the CHPS compounds, were analyzed. This time savings per month could be translated into time for productive work which has strong relation with community development.

From the survey results of Figure 7 , it is evident that access to electricity and improved healthcare services have more significant impact on females and children in rural agro-based communities than males. Results of this statistical analysis is presented in Section 3.4. On the average, time savings of 43 hours and 21 hours per month were reported for females and children, respectively. The time savings translate to available time of about 1 week ( 43 hours) and 3 days (21 hours) for productive work for the females and children, respectively, in the communities. It is important to note that in many rural agro-based communities in developing countries, female and children are usually the workforce engaged in various farming activities that results in significant productivity and community development [35-37, 43]. It is therefore argued that access to electricity that helps to improve healthcare and increases time availability for women to engage in productive work can result in significant socioeconomic development of societies [23].
3.4. Statistical Analysis of Time Savings due to Electricity Access in the CHPS Compounds. In order to ascertain the statistical significance of the time savings for females and children compared to that for males, the concept of hypothesis testing presented above (Section 2.6) was applied to the data collected on the field. Table 6 summarizes the results of the statistical analysis at significance level $\alpha=0.05$. From statistical tables, the critical $Z$ value for a right-tailed test under this significance level is $Z_{\mathrm{c}}=1.64$. The rejection region for this right-tailed test is therefore $\{Z: Z>1.64\}$.

From Table 6 , since the calculated $Z$ value for females and males is $Z=33.0>Z_{\mathrm{c}}=1.64$, it is concluded that the null hypothesis is rejected. Similarly, the calculated $Z$-score for children and males is $Z=5.6>Z_{\mathrm{c}}=1.64$, and therefore, the null hypothesis is rejected. In addition, since the $P$ values are zeros which are less than 0.05 , the null hypothesis is rejected. From the hypothesis testing, since the null hypothesis is rejected, the alternate hypothesis that "improved health conditions of females and children lead to more time savings (availability) that can potentially be used to undertake productive activities for socioeconomic development in rural agro-based communities than males" is accepted.

\section{Conclusion}

In this study, analysis has been conducted on how access to electricity can potentially improve community health and development in rural energy-deprived communities in developing countries, with a case study in Ghana. From this study, the following conclusions are made:

(i) For the $3.0 \mathrm{kWp}$ solar systems installed at the study sites, there are excess electricity in the magnitude of $148-304 \mathrm{kWh}$ per month that could be used by ESCOs to generate income for the maintenance and operations of the systems, which is critical for their sustainability

(ii) It was determined that electricity access in the CHPS compounds has improved healthcare service delivery resulting in positive health outcomes which translates to a healthier community that is always needed for community development

(iii) From the results of hypothesis testing, it has been determined that access to electricity in the CHPS compounds has more impact on females and children than males. Better health conditions of females and children lead to more time savings that can 
potentially be used to undertake productive activities for socioeconomic development in rural agro-based communities

4.1. Further Studies. The present study has analyzed electricity access in CHPS compounds and how it can improve healthcare service delivery in remote off-grid communities in developing countries, with a case study in Ghana. Inferring from the data obtained from outpatient records, percentage drops in reported cases of ailments in the CHPS compounds were determined. Whilst the authors believe that the electricity access has contributed to these drops in reported ailment cases, it is important to mention that these positive health outcomes could be ascribed to multiple factors. Future studies to decouple these factors and determine the specific correlation between energy access and improved health outcomes are worth investigating.

\section{Data Availability}

The [electricity consumption data and the questionnaires/respondent data] used to support the findings of this study are available from the corresponding author upon request.

\section{Conflicts of Interest}

We write to confirm that there is no conflict of interest with the funding agency for the publication of this manuscript. Approval has been obtained from our funding agency to publish the content of this manuscript.

\section{Acknowledgments}

The solar PV system on which this study was done was provided by the United Nations Foundation. However, the article processing fee (APA) will be paid by the Office of Grants and Research at the Kwame Nkrumah University of Science and Technology. The authors would want to thank the United Nations Foundation (UNF) for providing funds to undertake this study. In addition, the authors are thankful to the inhabitants, the community healthcare providers, and the community leaders for their support during the data collection for the survey study.

\section{References}

[1] IEA, World Energy Outlook 2017, OECD Publishing, Paris, 2017, https://www.iea.org/bookshop/750-World_Energy_ Outlook_2017.

[2] K. Uddin, G. Prinsloo, J. Marco, and P. Jennings, "TechnoEconomic Analysis of the Viability of Solar Home Systems Using Lithium- ion Batteries in Sub-Saharan Africa," Energy Procedia, vol. 138, pp. 267-272, 2017.

[3] T. Van Gevelt, C. C. Holzeis, S. Fennell et al., "Achieving universal energy access and rural development through smart villages," Energy for Sustainable Development, vol. 43, pp. 139142, 2018.

[4] United Nations, Transforming our world: the 2030 agenda for sustainable development, 2015, https://sustainabledevelopment.
un.org/content/documents/2125203020AgendaforSustainable Developmentweb.pdf.

[5] F. Riva, H. Ahlborg, E. Hartvigsson, S. Pachauri, and E. Colombo, "Electricity access and rural development: Review of complex socio-economic dynamics and causal diagrams for more appropriate energy modelling," Energy for Sustainable Development, vol. 43, pp. 203-223, 2018.

[6] W. G. Santika, M. Anisuzzaman, P. A. Bahri, G. M. Shafiullah, G. V. Rupf, and T. Urmee, "From goals to joules: A quantitative approach of interlinkages between energy and the Sustainable Development Goals," Energy Research \& Social Science, vol. 50, pp. 201-214, 2019.

[7] C. W. Shyu, "Ensuring access to electricity and minimum basic electricity needs as a goal for the post-MDG development agenda after 2015," Energy for Sustainable Development, vol. 19, pp. 29-38, 2014.

[8] L. R. Valer, A. Mocelin, R. Zilles, E. Moura, and A. C. S. Nascimento, "Assessment of socioeconomic impacts of access to electricity in Brazilian Amazon: case study in two communities in Mamiraua Reserve," Energy for Sustainable Development, vol. 20, pp. 58-65, 2014.

[9] D. Zhang, J. Li, and P. Han, “A multidimensional measure of energy poverty in China and its impacts on health: An empirical study based on the China family panel studies," Energy Policy, vol. 131, pp. 72-81, 2019.

[10] A. Pueyo and M. Maestre, "Linking energy access, gender and poverty: a review of the literature on productive uses of energy," Energy Research \& Social Science, vol. 53, pp. 170-181, 2019.

[11] D. C. Baruah and C. C. Enweremadu, "Prospects of decentralized renewable energy to improve energy access: A resourceinventory-based analysis of South Africa," Renewable and Sustainable Energy Reviews, vol. 103, pp. 328-341, 2019.

[12] A. F. Crossland, O. H. Anuta, and N. S. Wade, "A sociotechnical approach to increasing the battery lifetime of offgrid photovoltaic systems applied to a case study in Rwanda," Renewable Energy, vol. 83, pp. 30-40, 2015.

[13] D. Palit, "Solar energy programs for rural electrification: experiences and lessons from South Asia," Energy for Sustainable Development, vol. 17, no. 3, pp. 270-279, 2013.

[14] M. M. Rafique, H. M. S. Bahaidarah, and M. K. Anwar, "Enabling private sector investment in off-grid electrification for cleaner production: optimum designing and achievable rate of unit electricity," Journal of Cleaner Production, vol. 206, pp. 508-523, 2019.

[15] S. Few, O. Schmidt, and A. Gambhir, "Energy access through electricity storage: Insights from technology providers and market enablers," Energy for Sustainable Development, vol. 48, pp. 1-10, 2019.

[16] C. O. Onyeka and B. C. Oranekwu-Okoye, "Economic feasibility of solar PV system for rural electrification in sub- Sahara Africa," Renewable and Sustainable Energy Reviews, vol. 82, pp. 2537-2547, 2018.

[17] H. Rezk, M. A. Ali, and C. Ghenai, "Performance evaluation and optimal design of stand-alone solar PV-battery system for irrigation in isolated regions: A case study in Al Minya (Egypt)," Sustainable Energy Technologies and Assessments, vol. 36, article 100556, 2019.

[18] A. Franco, M. Shaker, D. Kalubi, and S. Hostettler, "A review of sustainable energy access and technologies for healthcare facilities in the Global South," Sustainable Energy Technologies and Assessments, vol. 22, pp. 92-105, 2017. 
[19] E. Mills, "Identifying and reducing the health and safety impacts of fuel-based lighting," Energy for Sustainable Development, vol. 30, no. 1, pp. 39-50, 2016.

[20] S. Oum, "Energy poverty in the Lao PDR and its impacts on education and health," Energy Policy, vol. 132, pp. 247-253, 2020.

[21] D. Hernández and E. Siegel, "Energy insecurity and its ill health effects: a community perspective on the energy-health nexus in New York City," Energy Research \& Social Science, vol. 47, pp. 78-83, 2019.

[22] T. Zhang, X. Shi, D. Zhang, and J. Xiao, "Socio-economic development and electricity access in developing economies: A long-run model averaging approach," Energy Policy, vol. 132, pp. 223-231, 2019.

[23] C. W. Njiru and S. C. Letema, "Energy poverty and its implication on standard of living in Kirinyaga, Kenya," Journal of Energy, vol. 2018, Article ID 3196567, 12 pages, 2018.

[24] M. Orosz, Q. Altes-Buch, A. Mueller, and V. Lemort, "Experimental validation of an electrical and thermal energy demand model for rapid assessment of rural health centers in subSaharan Africa," Applied Energy, vol. 218, pp. 382-390, 2018.

[25] United Nations Foundation, "Health facility energy needs assesment -Ghana," Ghana Country Summary Report, 2015.

[26] Ghana Health Service, National community-based health planning and services: accelerating attainment of universal health coverage and bridging the access inequality gap, 2016.

[27] ACCA, "Key health challenges in Ghana," Association of Chartered Certified Accountants; Survey report, 2013.

[28] D. A. Quansah and M. S. Adaramola, "Ageing and degradation in solar photovoltaic modules installed in northern Ghana," Solar Energy, vol. 173, pp. 834-847, 2018.

[29] J. Lloyd and J. Cheyne, "The origins of the vaccine cold chain and a glimpse of the future," Vaccine, vol. 35, no. 17, pp. 2115-2120, 2017.

[30] S. McCarney, J. Robertson, J. Arnaud, K. Lorenson, and J. Lloyd, "Using solar-powered refrigeration for vaccine storage where other sources of reliable electricity are inadequate or costly," Vaccine, vol. 31, no. 51, pp. 6050-6057, 2013.

[31] Ghana Health Service, The health sector in Ghana - facts and figures, 2015.

[32] D. A. Quansah, M. S. Adaramola, G. K. Appiah, and I. A. Edwin, "Performance analysis of different grid-connected solar photovoltaic (PV) system technologies with combined capacity of $20 \mathrm{~kW}$ located in humid tropical climate," International Journal of Hydrogen Energy, vol. 42, no. 7, pp. 46264635, 2016.

[33] C. D. Montgomery, C. G. Runger, and F. N. Hubele, Engineering Statistics (5th edition), 2013.

[34] T. J. McClave, P. G. Benson, and T. T. Sincich, Statistics for Business and Economics (12th edition), 2012.

[35] N. Rao, H. Gazdar, D. Chanchani, and M. Ibrahim, "Women's agricultural work and nutrition in South Asia: From pathways to a cross-disciplinary, grounded analytical framework," Food Policy, vol. 82, pp. 50-62, 2019.

[36] L. VitaDe, M. Mari, and S. Poggesi, "Women entrepreneurs in and from developing countries: evidences from the literature," European Management Journal, vol. 32, no. 3, pp. 451-460, 2014.

[37] K. M. Yount, Y. F. Cheong, L. Maxwell, J. Heckert, E. M. Martinez, and G. Seymour, "Measurement properties of the project-level Women's Empowerment in Agriculture Index," World Development, vol. 124, article 104639, 2019.

[38] E. L. Lehmann and P. J. Romano, Testing Statistical Hypotheses, Springer Science and Business Media, LLC, 3rd edition, 2008.

[39] S. Hartshorn, Hypothesis Testing: A Visual Introduction to Statistical Significance, 2015.

[40] A. Brew-Hammond, "Energy access in Africa: challenges ahead," Energy Policy, vol. 38, no. 5, pp. 2291-2301, 2010.

[41] PURC, Approved 2019-2020 electricity tariffs; Public Utility and Regulatory Commission, Ghana, pp. 1-3, 2019.

[42] E. B. Hagan, "Renewable energy policy review, identification of gaps and solutions in Ghana," in Regulatory Framework of Ghana's Energy Sector, Ghana Energy Commission, 2015, http://www.energycom.gov.gh.

[43] A. Padilla-meléndez and A. M. Ciruela-lorenzo, "Female indigenous entrepreneurs, culture, and social capital. The case of the _Quechua_community of Tiquipaya (Bolivia)," Women's Studies International Forum, vol. 69, pp. 159-170, 2018. 